\title{
DEVELOPMENT OF A HIGH-RESOLUTION NEARSHORE WAVE FORECASTING/HINDCASTING SYSTEM FOR THE ITALIAN COASTS
}

\author{
Catini $F .{ }^{1}$, Montagna $F .{ }^{1}$, Franco L. ${ }^{1}$, Bellotti $G .{ }^{1}$ Corsini $S .{ }^{2}$, Inghilesi $R^{2}$ and Orasi $A .^{2}$
}

\begin{abstract}
This paper describes a research aimed at developing a high-resolution nearshore wave forecasting/hindcasting system for the Italian coasts. Data recorded by buoys located in shallow water are compared with hindcasted data. The model uses the results of the well-tested large scale meteorological forecasting system named 'Idro-meteo-mare' (SIMM) managed by ISPRA, the Italian Agency for the Environmental Protection and Research, as wind input for WAM and SWAN models. Two different approaches are used for the Adriatic and the Tyrrhenian/Ligurian Sea. In the first eastern basin two/three SWAN nested grids have been used, while in the second western basins two WAM nested grids and a finer SWAN grid have been used. Both methodologies have shown a good accuracy and and a reasonable level of efficiency.
\end{abstract}

Keywords: wave forecasting; nearshore; WAM; SWAN ; Italian coast

\section{INTRODUCTION}

Wave predictions in deep waters have experienced significant developments during the last few decades and the skill of the state of the art models has been shown to be generally improving. However, the predictions are very sensitive to the wind fields used, as demonstrated by various authors (Teixeira et al., 1995; Holthuijsen, et al., 1996). Wave predictions near the coast are subjected to more complicated physics than in deep water, due to the greater influence of bathymetry and breaking processes near the shore, which, combined with the uncertainty from wind models, make wave modeling in coastal waters still a challenge.

Many meteorological centers produce wave forecasts for the Mediterranean Sea. Most of these tend to underestimate the wind velocity and consequently the wave height. The reason is that global meteorological models have a too poor spatial resolutions for restricted seas such as the North Adriatic Sea. Cavaleri and Sclavo 2006 have shown that the results can be highly improved using nested models with high resolution grids. This motivated the implementation of Limited Area Models over the Mediterranean Sea such the one used in this work. High quality re-analysis databases such for example HIPOCAS (Ratsimandresy et al. 2008) have also been obtained using this approach.

However, while it is generally accepted that wind predictions can improveusing higher resolution models, it is not clear if the grid resolution does play an important role in wave prediction modules. In deep waters areas, where the water depth is larger than say $100 \mathrm{~m}$, it is unlikely that a better description of the bathymetry, that could be achieved using high resolution grids, can give significant improvements. On the contrary in shallow waters regions, such those near to coasts, it is reasonable to expect that nested small scale grids can give better results than coarse ones.

The new coastal wave forecasting system uses the results of the well-tested large scale meteorological forecasting system named 'Idro-meteo-mare' (SIMM) managed by ISPRA, the Italian Agency for the Environmental Protection and Research. The key point of this work is that a new highresolution wave forecasting system, based on multi-nested on-way chains of WAM/SWAN models (Holthuijsen et al., 1989), running on several nearshore grids covering the Italian coasts has been applied. The boundary and initial conditions for the SWAN finer grids are obtained using the results of the larger scale runs based on the WAM model in the Thyrrhenian Sea, while the wind field is that produced on the large scale at $10 \mathrm{~km}$ resolution by QBOLAM (Buzzi et al., 1994; meteorological forecasting). An accurate validation and calibration procedure is being carried out by comparing the results of the system against available shallow-water directional wave measurements.

Although many buoys are operating along the Italian coast, most of them are in deep water, so just few nearshore wave recording stations are available to calibrate and validate the model. In order to carry out an accurate calibration few storms have been selected for each specific area under study. The final purpose of this work is to improve the accuracy and reliability of the wave forecasting system available on the ISPRA website, where the results of a coarse WAM model are already available.

\footnotetext{
${ }^{1}$ DSIC-University of Roma TRE via V.Volterra 62, 00146 Rome, Italy

${ }^{2}$ ISPRA-Istituto Superiore per la Protezione e la Ricerca Ambientale, via Curtatone 3 - 00185 Rome, Italy
} 


\section{THE DATA}

Along the Italian coast wave buoys have been installed since the '70. The largest buoy network is the RON (Rete Ondametrica Nazionale) (figure 1a) and it is composed by 15 directional wave buoys (8 of them operational since 1989). The network evaluates the main synthetic sea state parameters such as significant wave height (Hs), peak period (Tp), mean period (Tm) and mean direction (Dm) in deep water every 30 minuts. Beside RON, many other stations have been placed in time along the coast (figure 1b) in shallow water, allowing to study wave propagation nearshore. In this work we mostly consider a selection of shallow water stations. Their characteristics are summarized in table 1.
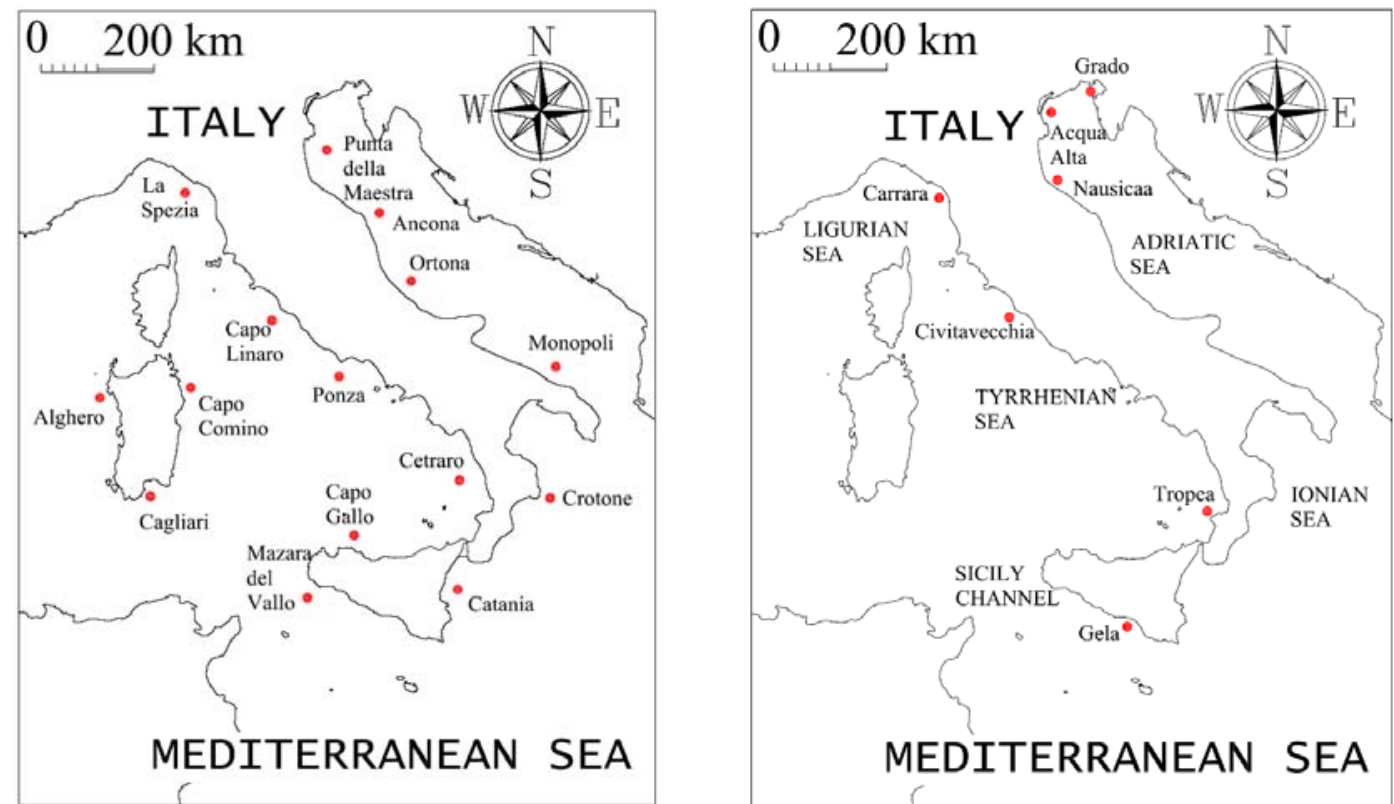

Fig. 1.a:Italian deepwater wave buoy network RON, as operational in 2010. Fig1.b: Layout of the shallow water stations of Grado, Acqua Alta, Nausicaa, Carrara, Civitavecchia, Tropea and Gela

\begin{tabular}{|l|l|l|l|l|c|}
\hline \multicolumn{7}{|c|}{ Tab. 1:location of the wave recording stations } \\
\hline \multicolumn{1}{|c|}{ NAME } & \multicolumn{1}{c|}{ LAT } & \multicolumn{1}{c|}{ LONG } & DEPTH(m) & YEARS & OWNERS \\
\hline ACQUA ALTA & $45^{\circ} 18.8^{\prime} \mathrm{N}$ & $12^{\circ} 30^{\prime} .5^{\prime} \mathrm{E}$ & 16 & $1978-2010$ & CNR \\
\hline NAUSICAA & $44.2155^{\circ} \mathrm{N}$ & $12.476^{\circ} \mathrm{E}$ & 10 & since 2007 & ARPA \\
\hline GRADO & $45.576^{\circ} \mathrm{N}$ & $14.257^{\circ} \mathrm{E}$ & 20 & $2001-2003$ & Region Friuli \\
\hline TROPEA & $38.687^{\circ} \mathrm{N}$ & $15.895^{\circ} \mathrm{E}$ & 50 & $2003-2004$ & Region Calabria \\
\hline GELA & $37.014^{\circ} \mathrm{N}$ & $14.052^{\circ} \mathrm{E}$ & 45 & since 2002 & ENI \\
\hline CIVITAVECCHIA & $42.00^{\circ} \mathrm{N}$ & $11.777^{\circ} \mathrm{E}$ & $35-50$ & $1994-2003$ & ENEL \\
\hline CARRARA & $44.021^{\circ} \mathrm{N}$ & $10.036^{\circ} \mathrm{E}$ & 13.5 & since 2005 & Port Autority \\
\hline
\end{tabular}

\section{THE FORECASTING MODEL}

Nowadays one of the large scale forecasting system in the Mediterranean area is the SIMM (Sistema Idro-Meteo-Mare) operated by ISPRA (Istituto Superiore per la Protezione e la Ricerca Ambientale). It is composed by a sequence of numerical atmospheric and oceanographic models. The limited area meteorological model used in the system is called QBOLAM (Quadrics BOlogna Limited Area Model). It is composed by two high-resolution and very-high-resolution meshes, one nested into the other one-way. The run with the coarsest resolution, $30 \mathrm{~km}$, is called HR-QBOLAM (High Resolution $Q B O L A M$ ), the run with the finest resolution, $10 \mathrm{~km}$, is called VHR-QBOLAM (Very High Resolution $Q B O L A M$ ). It is nested on the grid of the previous run and it covers all the Mediterranean Sea. Its output temporal resolution is 3 hours.

Winds resulting from these models are then used as input for WAM (Wave Model, The WAMDI group, 1988) to predict waves field in the Mediterranean Sea (figure 2). The grid resolution is of 10 $\mathrm{km}$ and the output temporal resolution is 3 hours. Wave forecasting is run every $24 \mathrm{~h}$ with a 60 hours advance forecasting. These data are available on the ISPRA website. 
It is underlined that the spatial resolution of the available WAM model is not suitable when studying nearshore processes, because in this case a resolution of the order of at least $400 \mathrm{~m}$ is required, allowing to evaluate with more accuracy wave generation and propagation as well as shoaling and refraction. In order to overcome this problem the SWAN model (Simulating WAves Nearshore) is used in this work. It is a non-stationary third-generation wave model (Holthuijsen et al., 1989) aimed to obtaining realistic estimates of wave parameters in coastal areas, lakes and estuaries from given wind, bottom and current conditions. However, SWAN can be used on any scale relevant for windgenerated surface gravity waves. It uses both frequency and directional spectra and it is based on the wave action balance equation with sources and sinks. The model can simulate wave propagation in time and space, shoaling, refraction due to currents and depth. It also considers several sources and sinks: wave generation by wind, dissipation due to whitecapping, bottom friction and depth-induced breaking, reduction of spectral energy due to non-linear interactions (three and four wave interactions). Diffraction and reflection are not modeled by SWAN, so the accuracy of the model near obstacles or inside harbors is poor.

The two dimensional wave spectrum can be described by the spectral action balance equation as follows:

$$
\frac{\partial N}{\partial t}+\frac{\partial c_{x} N}{\partial x}+\frac{\partial c_{y} N}{\partial y}+\frac{\partial c_{\sigma} N}{\partial \sigma}+\frac{\partial c_{\theta} N}{\partial \theta}=\frac{S}{\sigma}
$$

where $N$ is the action density spectrum, which is equal to energy density spectrum divided by the relative frequency. In this equation, $\sigma$ and $\theta$ are wave relative frequency and wave direction, respectively. The first term in the left-hand side of the above equation represents the local rate of change of wave action density spectrum in time. The second and third terms represent propagation of wave action in geographical space with velocities $c_{x}$ and $c_{y}$ in $x$ and $y$-directions, respectively. The fourth term represents shifting of the relative frequency due to variations in depths and currents with propagation velocity $c_{\sigma}$ in $\sigma$ - space. The fifth term represents depth-induced and current-induced refraction with propagation velocity $c_{\theta}$ in $\theta$ - space. The expressions for all of propagation velocities are taken from linear wave theory. The term at the right-hand side of the wave action balance equation is the source term of energy density representing wave generation, energy dissipation and non-linear wave-wave interactions.

SWAN has been used in two different configurations. The first one, used in the semi-closed Adriatic Sea, consists in applying only a chain of SWAN nested runs, considering as a source the wind evaluated by the $10 \mathrm{~km}$ resolution SIMM vhr forecast/hindcast. The second, used in the Thyrrhenian Sea and in the Sicily channel, couples SWAN with $3 \mathrm{~km}$ resolution, parallel run of WAM cycle 4.5 model, considering at the boundary the waves calculated by the WAM and also the wind evaluated by VHR-QBOLAM as a source. When using SWAN directly on the entire basin it is not necessary to consider other boundary conditions because the wave field is all generated and propagated inside the considered area.

These two procedures allow to study nearshore wave propagation with the proper accuracy. For that reason the application of SWAN directly from wind data has been performed on the Adriatic Sea, while on the western seas SWAN has been coupled to the WAM model.

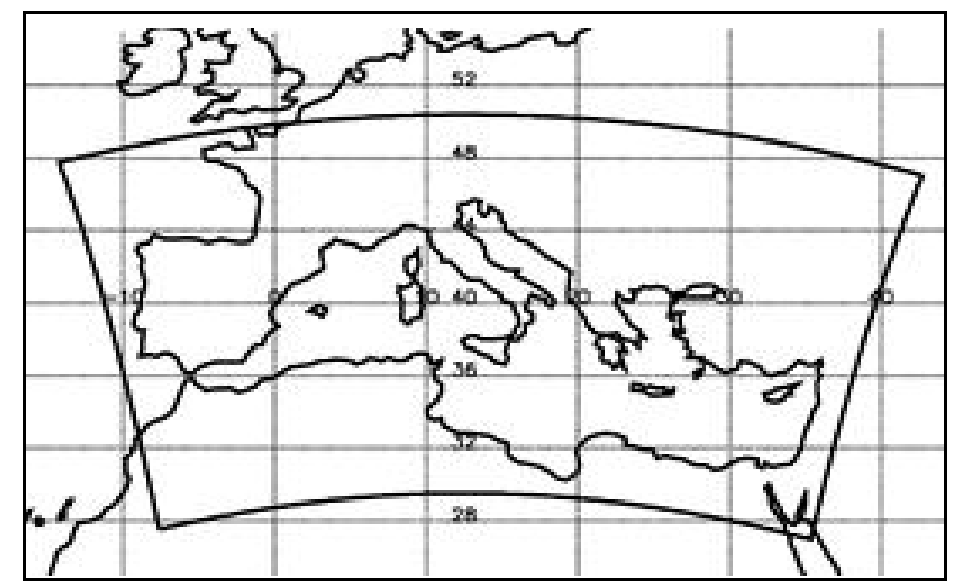

Fig. 2: The area covered by WAM model 


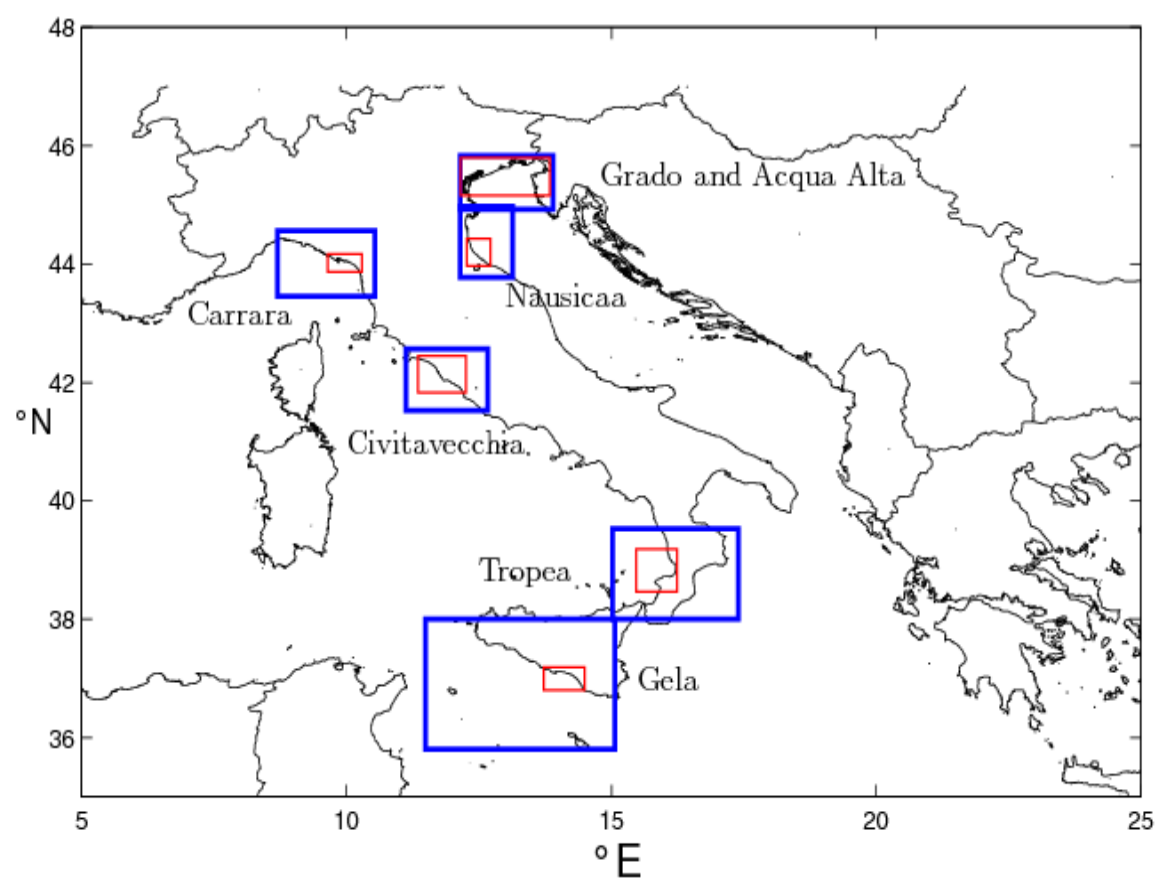

Fig. 3: Location of the areas used to validate the procedure and the model

\section{VALIDATION OF THE SYSTEM}

In order to carry out an accurate validation and calibration of the model chains, data recorded by shallow-water directional wave buoys have been used, so, firstly, the areas closest to the selected buoys along the Italian coast have been selected and then few storms for each specific area under study have been considered. In particular both procedures described in the previous chapter have been applied in different areas. SWAN output temporal resolution is 1 hour, so, in order to compare time series of Hs, Tp and Dm recorded by the buoys and SWAN results, it has been necessary to interpolate the buoy data every hour.

On the whole Adriatic sea SWAN model has been used directly from QBOLAM wind data and the results have been compared with data recorded at the stations Acqua Alta, Nausicaa and Grado, while on the Tyrrhenian Sea and on Sicily Strait SWAN has been applied from WAM data and in particular in the area of Marina di Carrara, Civitavecchia, Tropea and Gela. These areas are indicated in figure 3. It must be underlined that in this work the Gela area has not been analysed. In this validation process a comparison of wind data has also been conducted, using data recorded by the anemometric ISPRA stations nearest to the study area.

\section{The Adriatic Sea}

Wave propagation in the Adriatic Sea has been studied applying a chain of SWAN runs nested on three different grids (figure 4). The largest one, grid 1, covers the whole Adriatic Sea and this is based on the assumption that the contribution due to waves entering from the Otranto channel is negligible, so it is not necessary to use external boundary conditions. The coarsest grid has a resolution of $1 / 30$ degree and the coordinate system used is spherical. The finest domains have a resolution of 1/120 and $1 / 240$ degrees, corresponding to 800 and $400 \mathrm{~m}$.

The bathymetry has been interpolated on the 3 grids using the isolines of bathymetry provided by the Marine Hydrographic Institute on the reference frame UTM33T with a resolution of 1:100000, and a high-resolution grid, derived from the 30" GEBCO, with a resolution of 1/240 degrees provided by the ARPA-ER. In figure 5 it is possible to observe the increase of resolution of the three grids for the Northern Adriatic Sea. 

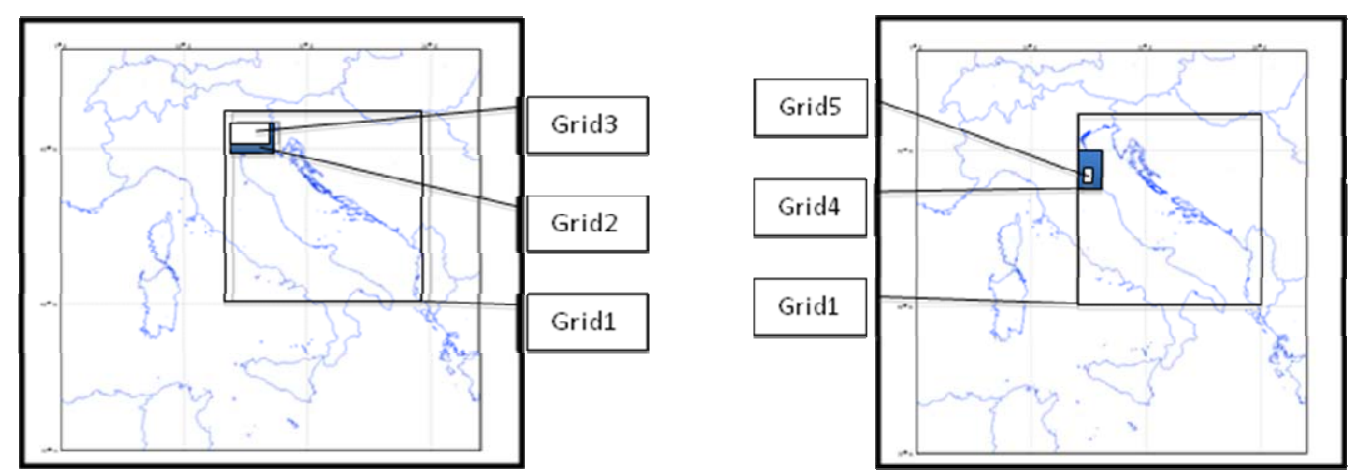

Fig. 4: Grids for the area of Grado and Acqua Alta (left), Nausicaa (right)
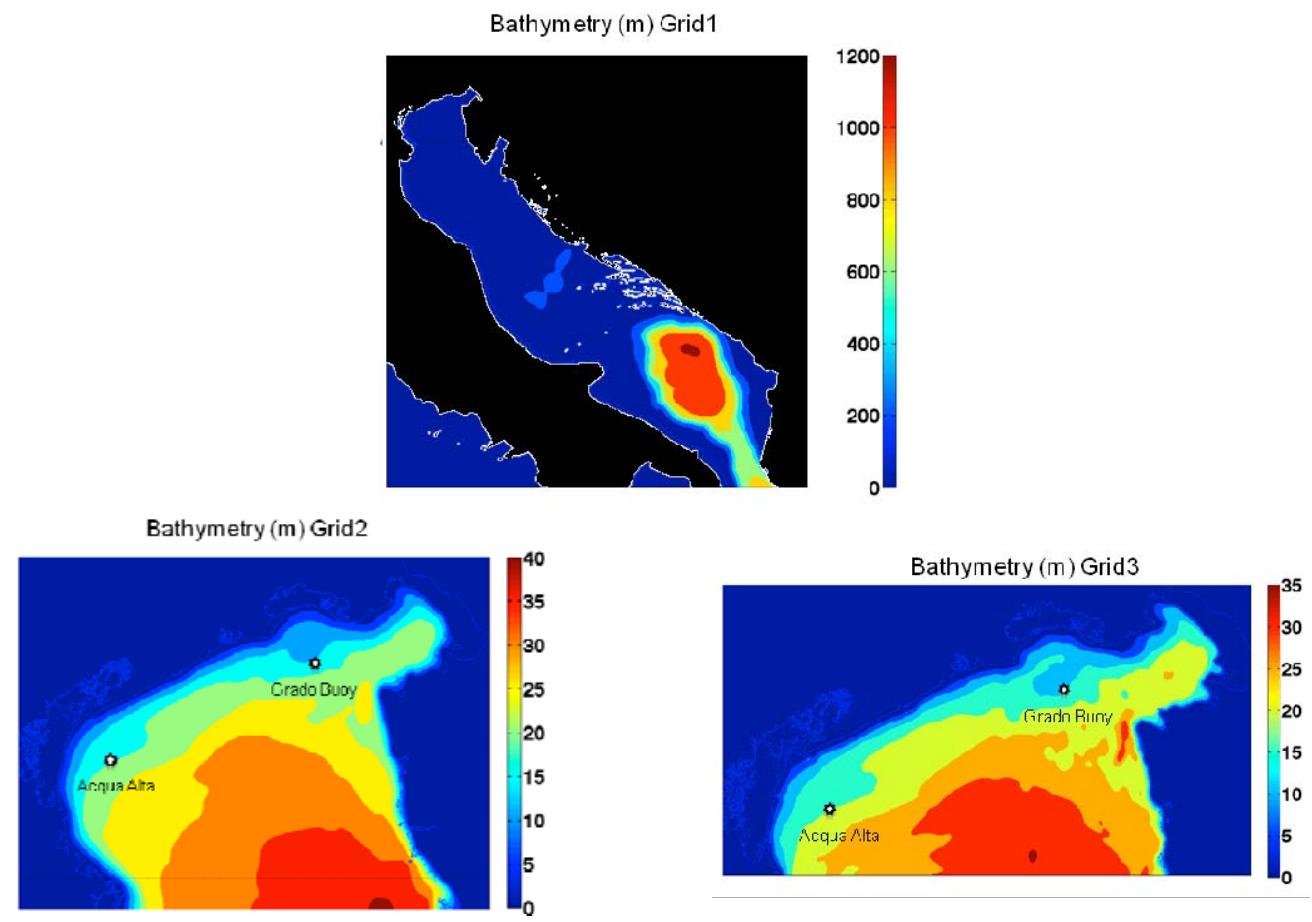

Fig. 5: Bathymetry: the whole Adriatic Sea, resolution 1/30 degree (upper panel); northern Adriatic Sea, resolution 1/120 degree (down left panel); northern Adriatic Sea, resolution 1/240 degree (down right panel)

It must be noted that the spatial resolution of the VHR-QBOLAM is $10 \mathrm{~km}$, so the forcing wind of each grid has been obtained applying a spatial interpolation of the data of the meteorological model to the SWAN grid cells. Moreover the temporal resolution of wind data from QBOLAM is 3 hours that is different from the temporal resolution of SWAN model (1 hour). For the validation of the model, five storms that have attacked Emilia Romagna coast between 2007 and 2008 and five in the Gulf of Venice and of Trieste between 2001 and 2003 have been selected. In this work, for sake of brevity, one storm for each of the two areas will be presented in detail.

Storms on Friuli coast. In the week 14-21 November 2002 a double-peak storm occurred along the Veneto and Friuli coast. It was both recorded by Acqua Alta and Grado stations. The Grado records are characterized by waves coming from S-SE. The highest recorded Hs was $3.37 \mathrm{~m}$. Figure 6 shows a comparison between recorded and computed $H s$ and here it is very evident that the numerical results are not influenced by the resolution of the SWAN mesh. The numerical model well evaluates Hs time series, in fact it can be observed that in this case recorded data and computed results are not only synchronized but they are almost well superimposed. There is an underestimation by the model and the maximum error is about $12 \%$. The comparison of wind data recorded at Trieste anemometer and forecasted data, shown in figure 7, presents, on the contrary, a little overestimation of the wind strength but the forecasted wind (red dashed line) well envelops the recorded wind speed (black line), being in phase. 
In order to evaluate the accuracy of the model estimation it is useful to view on a scatter diagram the wave height distribution for the 5 selected storms recorded at Grado site. In figure 8 SWAN predicted Hs against recorded Hs are plotted. It shows a moderate underestimation of the numerical model that decreases for the highest Hs. The correlation coefficient is 0.77 and it has been evaluated as:

$$
c o r r=\frac{\operatorname{cov}\left(H s_{o b s}, H s_{S W A N}\right)}{\operatorname{var}\left(H s_{o b s}\right) * \operatorname{var}\left(H s_{S W A N}\right)}
$$

where $\operatorname{cov}\left(H s_{\text {obs }}, H s_{S W A N}\right)$ is the covariance between recorded $H s$ and predicted by SWAN, $\operatorname{var}\left(H s_{\text {obs }}\right)$ represents the variance of the recorded $H s$ and $\operatorname{var}\left(H s_{S W A N}\right)$ represents the variance of the predicted $H s$. The number of data, $n$, used to evaluate the correlation is 411 .

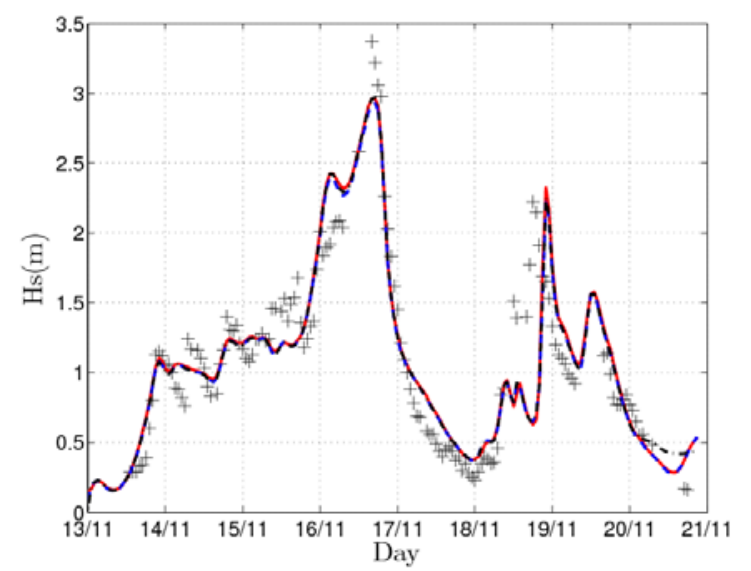

Fig. 6: Hs during the storm of the 14- 21 November 2002 recorded (black crosses), estimated by SWAN on grid1 (red dashed line), on grid2 (blue dashed line) and on grid3 (black dashed-dot line) for Grado site
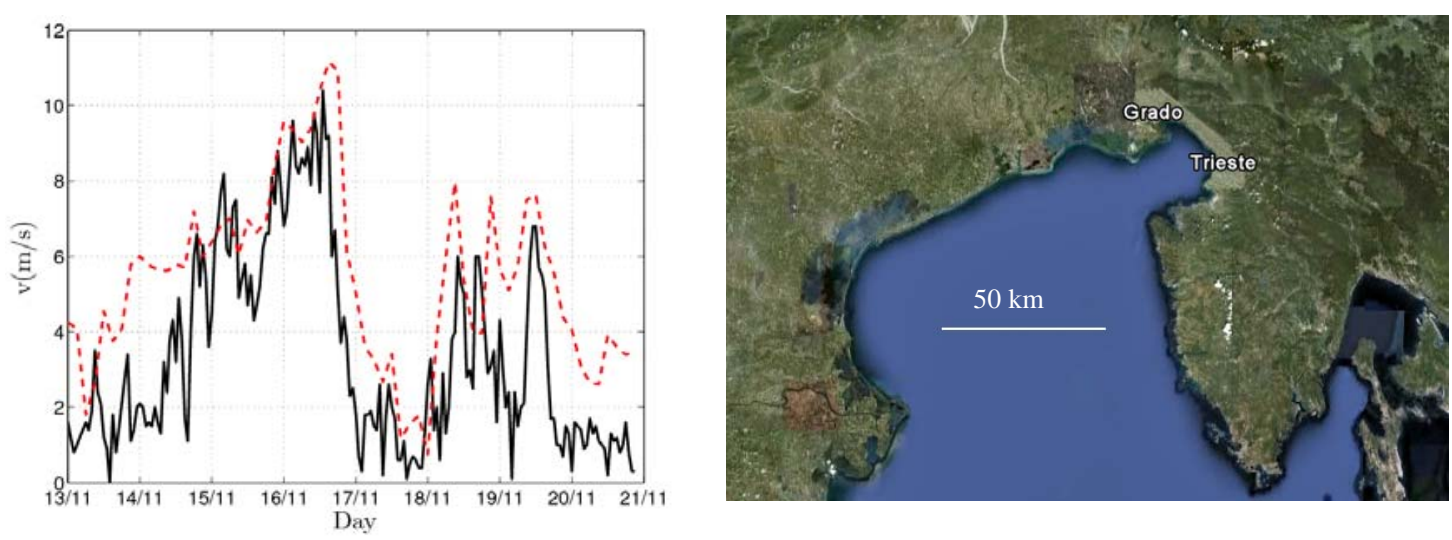

Fig.7a: Wind speed during the storm of the 14- 21 of November 2002 recorded by Trieste anemometer (black line) and estimated by VHR-QBOLAM (red dashed line) for Grado site. Fig. 7b: Grado and Trieste. 


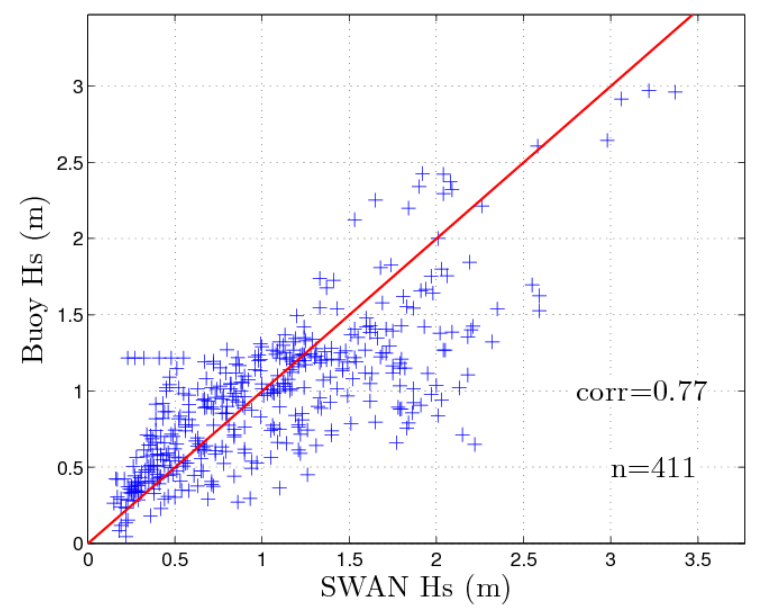

Fig.8: Scatter diagram for Grado site for all the analyzed storms. The correlation between recorded and predicted $\mathrm{Hs}$ is also indicated

Storms on Emilia Romagna coast. On the $19^{\text {th }}$ of October 2007 and on the following days, a moderate storm occurred along the Emilia Romagna coast and it was well recorded by the Nausicaa buoy off Cesenatico. The main wave direction was NE and in particular the sea states with a $H s$ larger than $2 \mathrm{~m}$ came from the sector $30^{\circ}-60^{\circ} \mathrm{N}$. The highest recorded Hs was $2.7 \mathrm{~m}$. Figure 9 shows a comparison between recorded and computed $H s$. It could be observed that the results obtained on nested grids do not evidence a clear improvement of the prediction. This could be due to the almost uniform bathymetry: the increasing spatial resolution does not change significantly the bottom conditions.

The model well evaluates the general behaviour of the storm, the growth phase, peaks and the decreasing phase are almost synchronized, but the model underestimates the peaks wave heights, reaching a maximum error of $40 \%$. When the highest peak occurs the underestimation is about $15 \%$. These errors could be related to the wind trend estimated by QBOLAM. The same underestimation could be found in the evaluation of the wave period, whose general behavior is well calculated by SWAN. Figure 10 shows the comparison between estimated wind speed and measured wind speed at Ravenna anemometer. Here an evident underestimation of the wind speed can be observed in the same days corresponding to the maximum errors in evaluating $H s$. It could also be noticed that, because of the different temporal sampling rate, wind recorded by the anemometer has more fluctuations than the modeled one. Finally the wave direction is well estimated by SWAN during the storm and the resulting mean direction is $50^{\circ} \mathrm{N}$.

Figure 11 shows SWAN predicted Hs against recorded Hs. It could be observed a general underestimation of the model, as confirmed by figure 9 . The correlation coefficient is 0.83 .

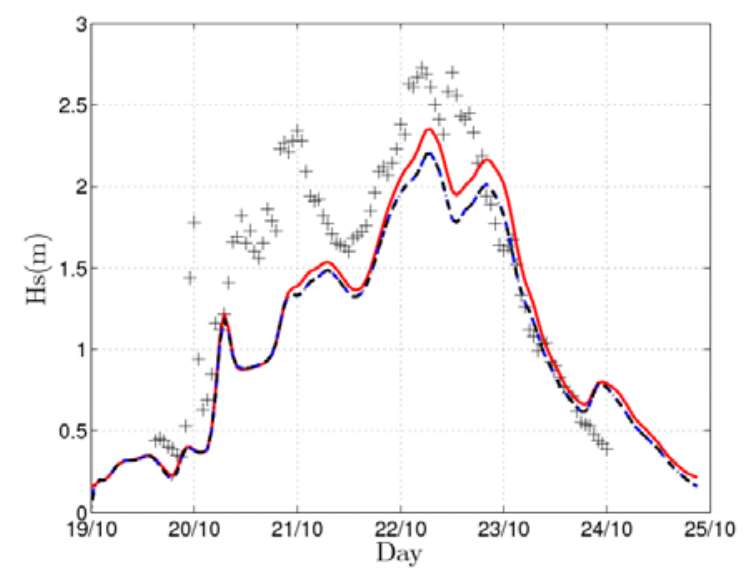

Fig. 9: Hs during the storm of the 22nd of October 2007 recorded (black crosses), estimated by SWAN on grid1 (red line), on grid4 (blue dashed line) and on grid5 (black dashed-dot line) for Nausicaa site 

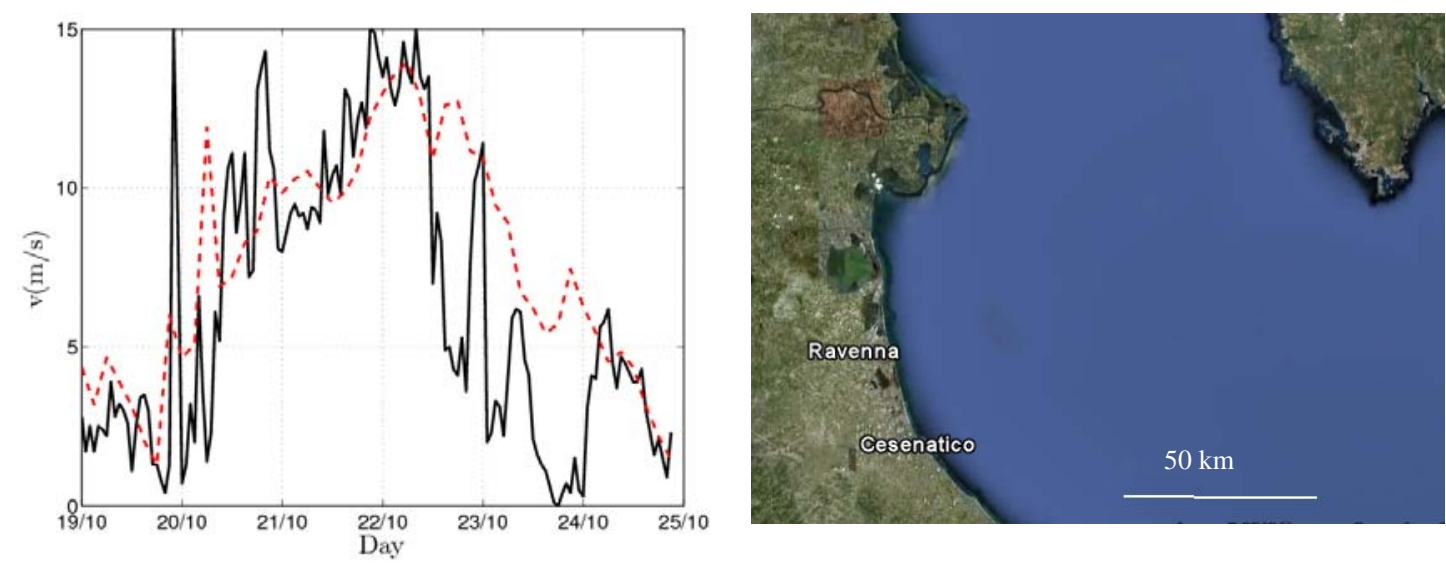

Fig.10a: Wind speed during the storm of the $22^{\text {nd }}$ of October 2007 recorded by Ravenna anemometer (black line) and estimated by VHR-QBOLAM (red dashed line) for Nausicaa site. Fig.10b: Ravenna and Cesenatico

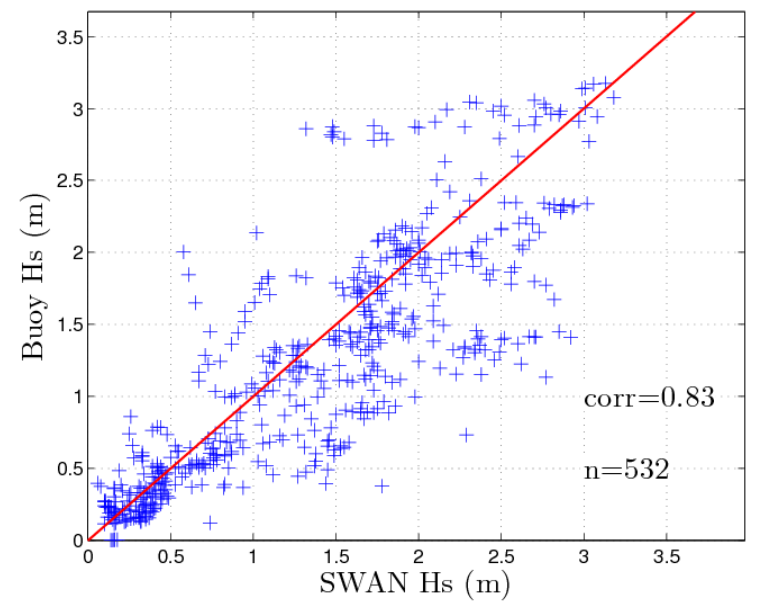

Fig.11: Scatter diagram for Nausicaa site for all the analyzed storms. The correlation between recorded and predicted $\mathrm{Hs}$ is also indicated

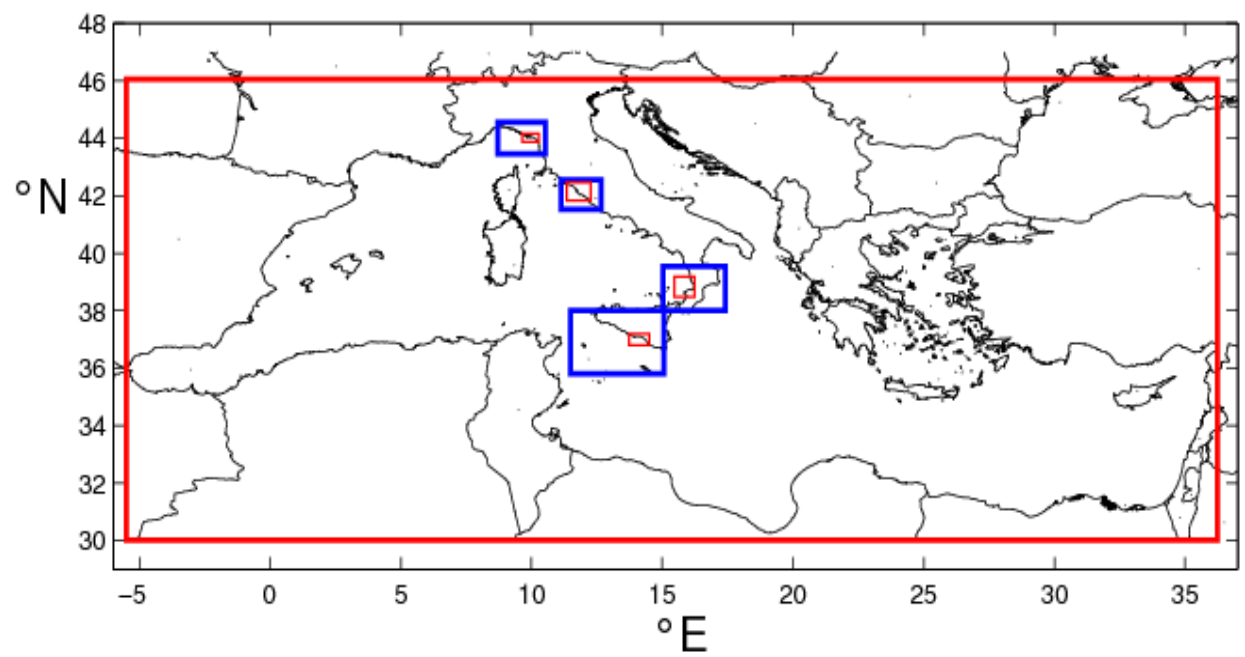

Fig.12: Western coasts selected areas. The grid on the whole Mediterranean (red line) and the finest grids 
The Western coasts.

On the western Italian coasts nearshore wave propagation has been studied considering three areas, one in the Ligurian Sea, off Marina di Carrara, two in the Tyrrhenian Sea, off Civitavecchia and Tropea (fig. 12).

The WAM model cycle 4.5, with a resolution 1/30 degree, has been used covering all the Mediterranean Sea. Then, on the three selected areas, a WAM 1/60 degree has been chain-nested on the mediterranean grid . This intermediate nesting was not expected to improve the results at all, but it was introduced in order to have a reasonable ratio (in the range of 2-4) between the resolution of the large-scale model grid and the coastal model grid. The last step has been to nest the coastal grid to the intermediate one with a final resolution 1/240 deg. On the costal grid the SWAN model was used to simulate nearshore processes. The scheme used for wave generation- whitecapping is the quasisaturation scheme proposed by Van der Westhuysen (1997). This scheme was developed in order to improve the SWAN results when sea-waves and swell are both present in the propagation process, which is useful when analyzing areas with long fetches, as for the western coasts. The bathymetry has been based as for the Adriatic Sea, on the bathymetric isolines provided by the Marine Hydrographic Institute on the reference frame UTM33T and using GEBCO (General bathymetry Chart of Oceans) by BODC (British Oceanographic Data Center) with a resolution $1 \frac{1}{2}$ degree.

Storms in the Ligurian Sea. On the 19th of March 2007 and on the following days a storm characterized by two wave peaks attacked the Tuscany and Ligurian coasts. The peak Hs recorded by Marina di Carrara buoy was $4.6 \mathrm{~m}$. Waves were coming from SW ( $230^{\circ} \mathrm{N}$ ). The map of figure 13 shows the results of WAM model on the Mediterranean Sea at the peak of the storm.

Figure 14 shows the comparison between recorded $H s$ time series and the series evaluated by the Mediterranean WAM model, by the nested WAM model and by the nested SWAN model. It is possible to observe a good agreement between recorded and simulated data and that there is not a great difference between the results of the different nested grids. The model evaluates correctly the first peak and its growth phase, while it underestimates with a significant time shift the second recorded peak. This is probably caused by the underestimation of the wind that is visible in figure 15 just before the 19th , winds recorded by Livorno anemometer show a peak of $10 \mathrm{~m} / \mathrm{s}$, while QBOLAM results at Marina di Carrara barely have $4 \mathrm{~m} / \mathrm{s}$. It must be observed that, because of the distance of the two sites, about $50 \mathrm{~km}$, this comparison is not completely reliable.

The scatter diagram of figure 16 shows a high correlation within recorded and estimated Hs with a correlation of about 0.82 . The model evaluates correctly also the wave direction that is almost constant at about $230^{\circ} \mathrm{N}$.

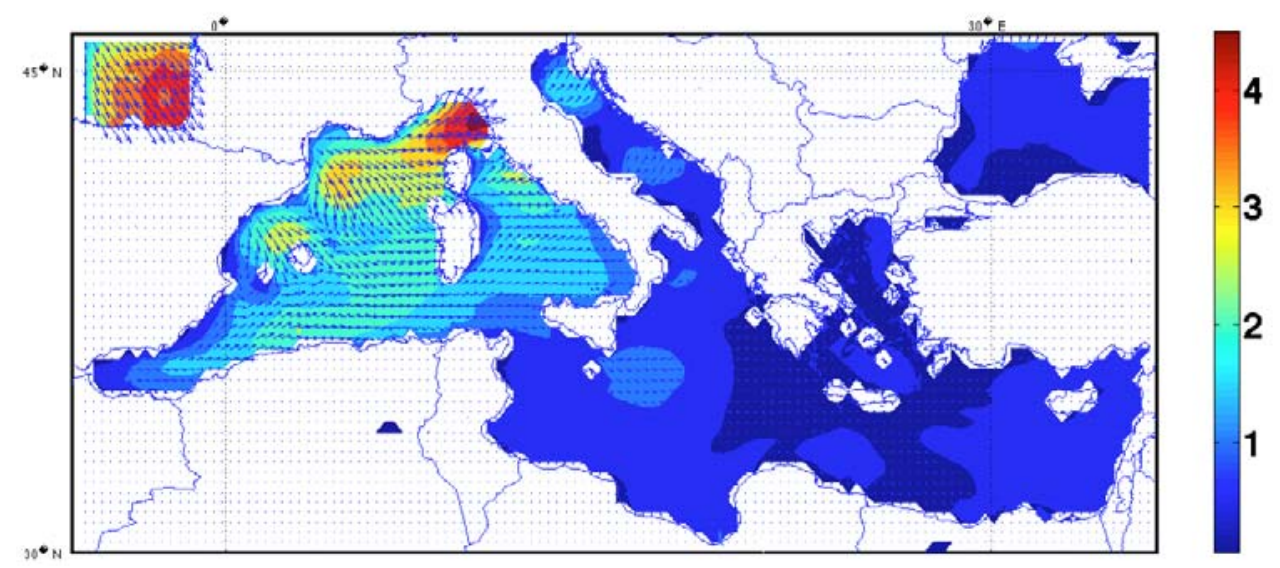

Fig.13: Forecasted Hs by WAM model on the $19^{\text {th }}$ March 2007 at 9:00 


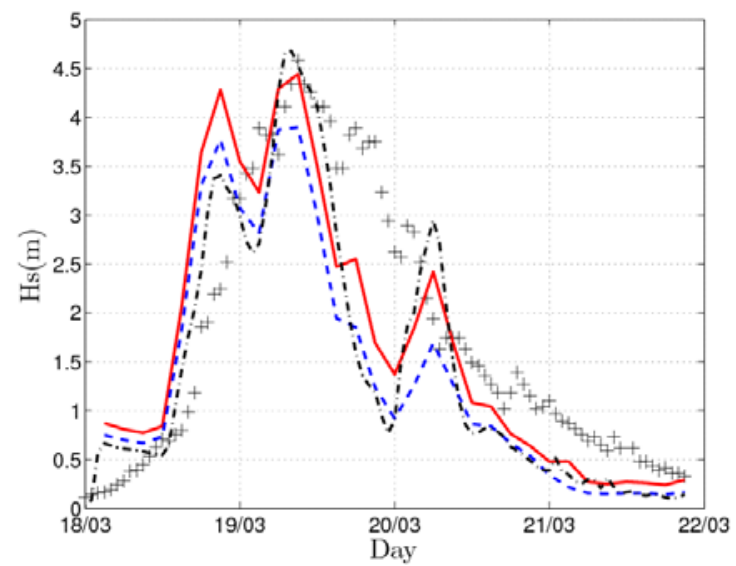

Fig. 14: Hs during the storm of the $19^{\text {th }}$ of March 2007 recorded (black crosses), estimated by WAM model on Mediterranean Sea (red line) and on the local grid (blue dashed line). SWAN estimated Hs on the high resolution grid (black dashed-dot line) for Marina di Carrara site
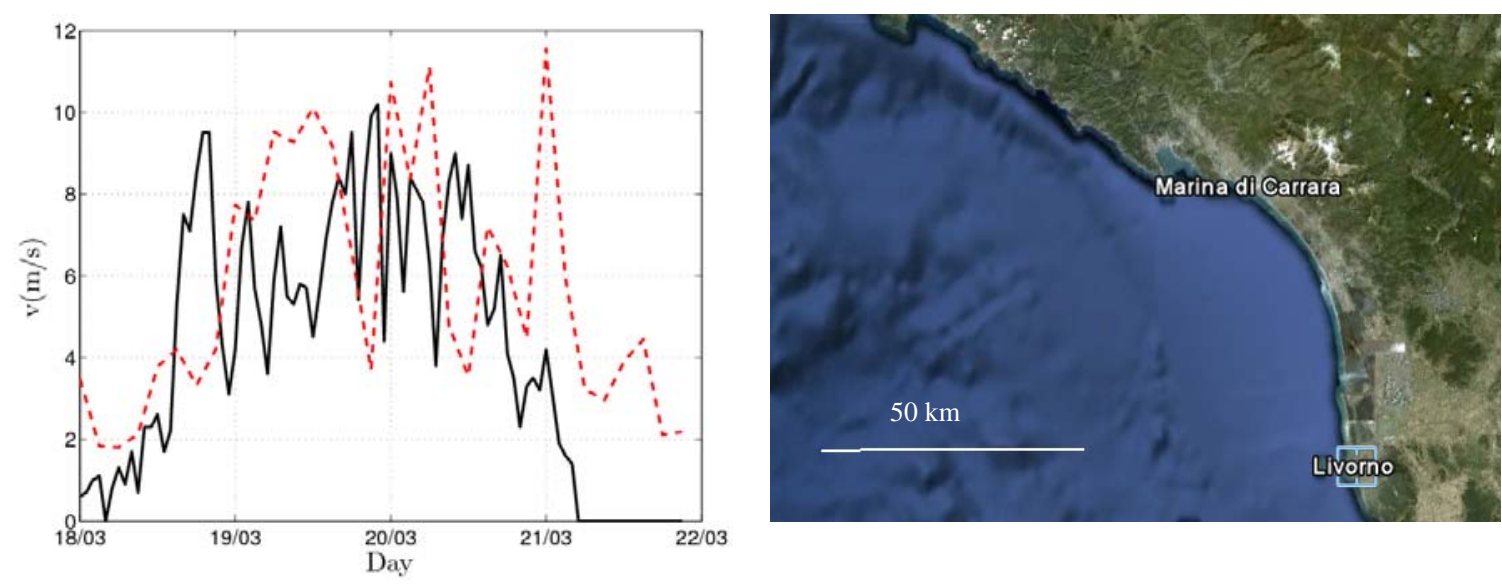

Fig.15a: Wind speed during the storm of the $19^{\text {th }}$ of March 2007 recorded by Livorno anemometer (black line) and estimated by VHR-QBOLAM (red dashed line) for Marina di Carrara site. Fig 15b: Marina di Carrara and Livorno

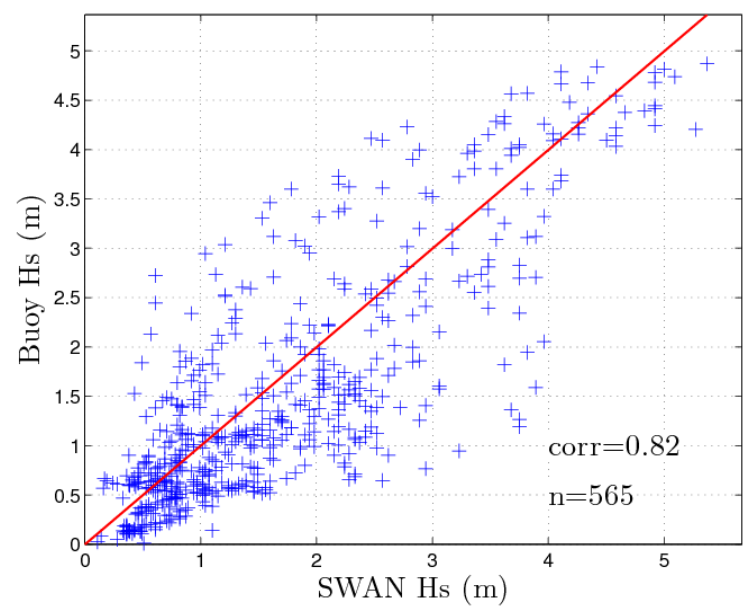

Fig.16: Scatter diagram for Marina di Carrara site for all analyzed storms. The correlation between recorded and predicted $\mathrm{Hs}$ is also indicated 
Storms in Central Tyrrhenian Sea. Between the 19 September 2002 and the 26 of the same month, Civitavecchia wave buoy recorded a storm with two peaks, the first of Hs=3.4 $\mathrm{m}$ and the second of $\mathrm{Hs}=2.86 \mathrm{~m}$, coming from about $240^{\circ} \mathrm{N}$. The comparison of figure 17 between recorded data, WAM and SWAN results shows an increase in accuracy due to the nested SWAN application. This last model evaluates correctly the growth and decrease peak phases but it underestimates the first peak Hs. The model follows the time series of the last peak, but, again, the values are underestimated. The comparison of wind data of figure 18 shows that the general wind trend is well simulated and that when there is the largest underestimation of $\mathrm{Hs}$, about $60 \%$, there is also a significant underestimation of the wind by QBOLAM.

The scatter diagram of figure 19 exhibits a very good correlation between the data. SWAN model also well evaluate the wave direction and the peak period, although it is a little bit underestimated.

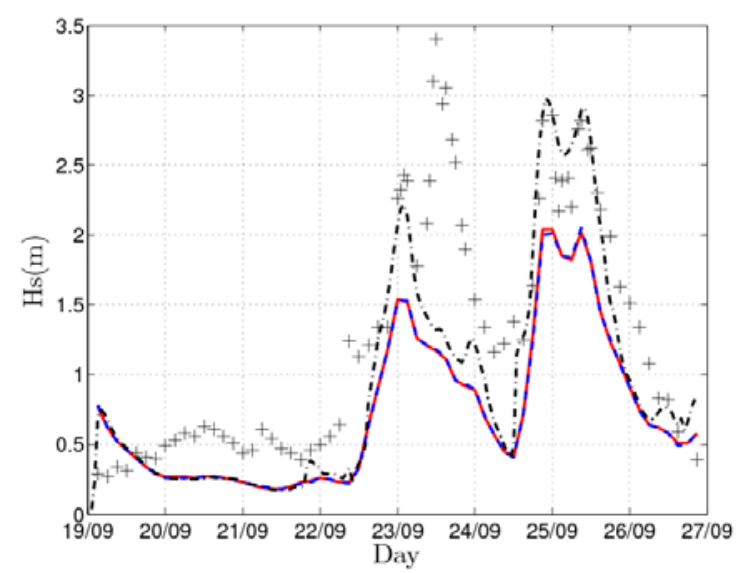

Fig. 17: Hs during the storm of the $23^{\text {rd }}$ of September 2002 recorded (black crosses), estimated by WAM model on Mediterranean Sea (red line) and on the local grid (blue dashed line) . SWAN estimated Hs on the high resolution grid (black dashed-dot line) for Civitavecchia site

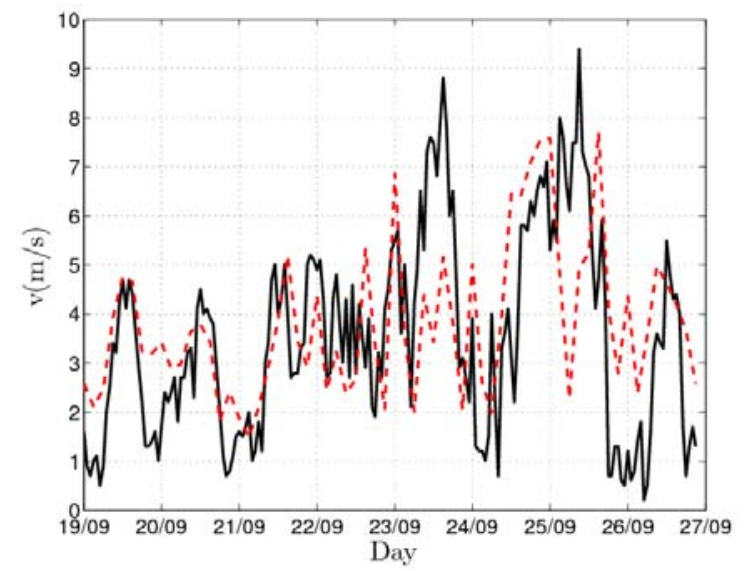

Fig.18: Wind speed during the storm of the $23^{\text {rd }}$ of September 2002 recorded by Civitavecchia anemometer (black line) and estimated by VHR-QBOLAM (red dashed line) for Civitavecchia site 


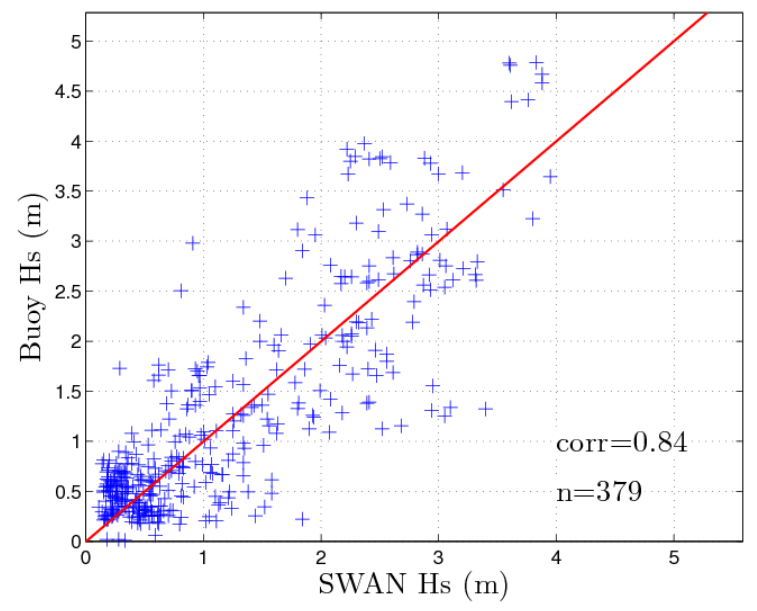

Fig.19: Scatter diagram for Civitavecchia site for all analyzed storms. The correlation between recorded and predicted $\mathrm{Hs}$ is also indicated

Storms in the South Tyrrhenian Sea. On the $9^{\text {th }}$ of October 2003 Tropea wave buoy recorded a peak Hs of $3.38 \mathrm{~m}$. Wave direction was included in the sector $275-305^{\circ} \mathrm{N}$.

Figure 20 shows a fairly good superposition of modeled and recorded Hs, except at the first peak that is a little overestimated by the model. In this case the error in the estimation of Hs might not due to the incorrect estimation of the local wind, that, as observed in figure 21, could have actually been underestimated by the model while it resulted in an actual overprediction of wave heights. However, again, the anemometer used to compare wind data, at Palinuro, is very far from Tropea (figure 21b), more than $150 \mathrm{~km}$. The scatter diagram of figure 22 shows a larger variability in the estimation of the highest Hs with an overall correlation of 0.69. In the storm here presented instead there is a good estimation of Hs peaks and this is coupled with a very good evaluation also of peak periods and wave directions.

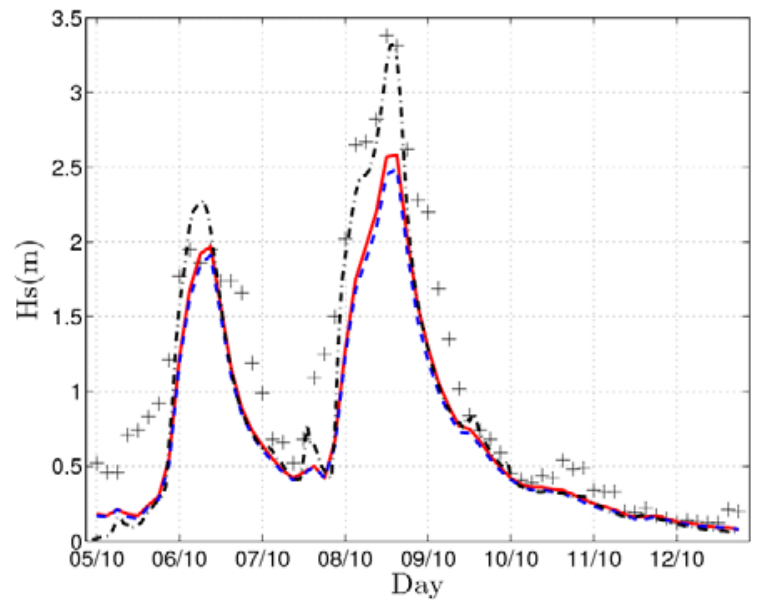

Fig. 20: Time history of Hs during the storm of the $9^{\text {th }}$ of October 2003 recorded (black crosses), estimated by WAM model on Mediterranean Sea (red line) and on the local grid (blue dashed line). SWAN estimated Hs on the high resolution grid (black dashed-dot line) for Tropea site 

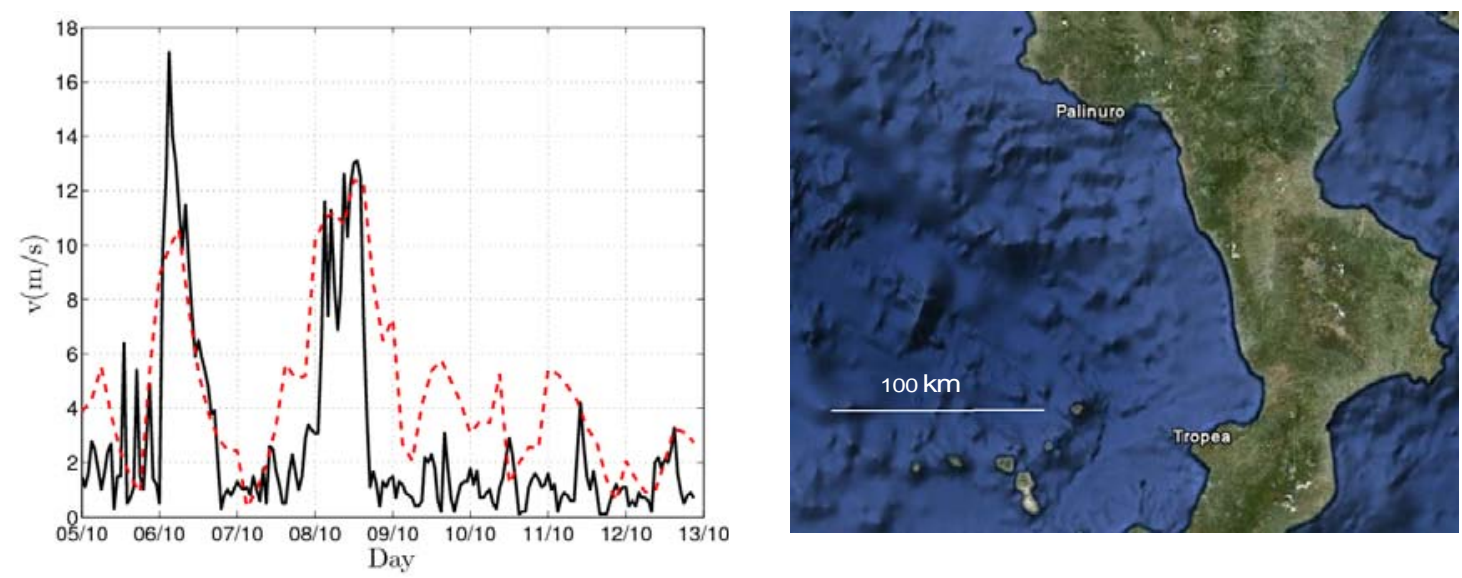

Fig.21a: Wind speed during the storm of the $9^{\text {th }}$ of October 2003 recorded by Palinuro anemometer (black line) and estimated by VHR-QBOLAM (red dashed line) for Tropea site. Fig. 21b: Tropea and Palinuro

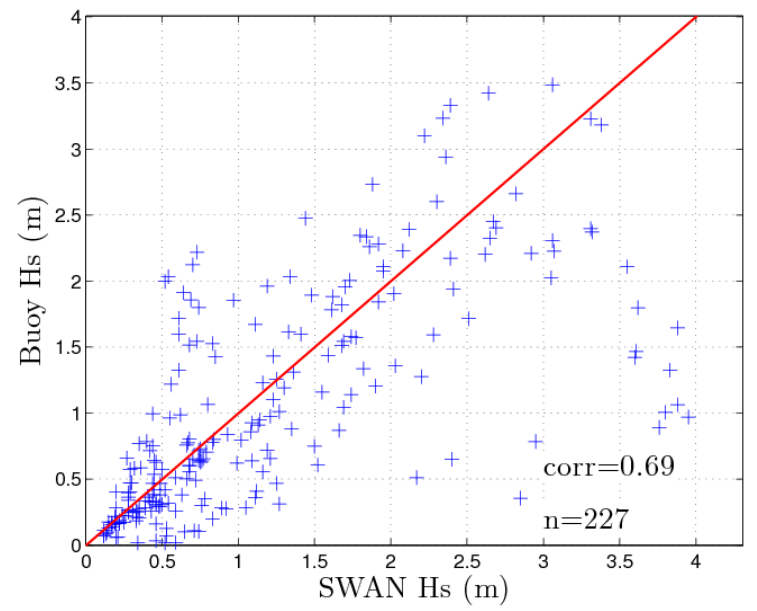

Fig.22: Scatter diagram for Tropea site for all five analyzed storms. The correlation between recorded and predicted $\mathrm{Hs}$ is also indicated

\section{CONCLUSIONS}

This work shows the applicability of a high-resolution nearshore wave forecasting/hindcasting system for a few selected coastal sea areas around Italy. It has been shown how the application of SWAN model in coastal areas can improve the accuracy of the simulation of sea storms on areas with specific orographic and bathymetric conditions. In each of the six selected sea areas 5 storms have been simulated, even if only one for each of the 5 areas is herewith presented. In particular SWAN has been applied on the Adriatic and Tyrrhenian Seas using two different approaches. Nested SWAN-only grids have been used on the Adriatic Sea, showing a good accuracy in the prediction of storm behaviour. It could also be observed that the increased resolution of the mesh does not improve the accuracy of the prediction. However the choice of a high spatial resolution grid $(400 \mathrm{~m})$ allows a good definition of the local coastal wave climate, which is helpful for design purposes.

On the Tyrrhenian Sea the coupling of WAM and SWAN shows, on the contrary, an evident increase of the accuracy on the predicted waves in the SWAN finest grid for the three analysed areas. It must also be underlined that storms in the Tyrrhenian Sea are more intense than in the Adriatic Sea making the prediction of wave peaks more difficult. Also the bathymetry varies significantry more in the Thyrrhenian Sea than in the Adriatic. This improvement can be observed on the scatter diagram of Tropea (figure 22). It also confirm the known wave height underestimation due to episodic incorrect reproduction of the wind field .

The correlation coefficient obtained is high for all the areas and it varies between 0.69 and 0.84 . This confirms the validity of the implemented method. 


\section{REFERENCES}

Buzzi A., Fantini M., Malguzzi P. and Nerozzi F. 1994. Validation of a limited area model in cases of mediterranean cyclogenesis: surface fields and precipitation scores. MeteoroL Atmos. Phys., 53:53671994.

Bertotti L. and Cavaleri L. On the influence of resolution on wave modelled results in the Mediterrnean Sea. Il nuovo cimento, 29 C, n.4, 2006

Cavaleri L. and Sclavo M. 2006. The calibration of wind and wave model data in the Mediterranean Sea. Coastal Engineering 53, 613-627.

Franco L., Piscopia R. Corsini S. and Inghilesi R. 2004. "L'Atlante delle onde nei mari italiani Italian Wave Atlas” Full Final Report, University of Roma TRE - APAT.

Holthuijsen L.H., Booij N. and Herbers T.H.C., 1989. A prediction model for stationary, shortcrested waves in shallow water with ambient currents, Coastal Engineering, 13, 23-54.

Holthuijsen L.H., Booji N., Bertotti L. 1996. The propagation of wind errors through ocean wave hindcasts. J. Offshore Mech. Arct. Eng. 118, 184-189.

Komen, Cavaleri, Donelan.Hasselmann,Hasselmann,Janssen, Dynamics and Modelling of Ocean Waves. Cambridge Universty Press, 1994

Ratsimandresy A.W., Sotillo M.G., Carretero Albiach J.C., Álvarez Fanjul E., Hajji H. 2008. A 44-year high-resolution ocean and atmospheric hindcast for the Mediterranean Basin developed within the HIPOCAS Project, Coastal Engineering 55,827-842.

SWAN Technical Manual, SWAN Cycle III version 40.81. Delft University of technology.

Teixeira, J.C., Abreu, M.P., Guedes Soares, C., 1995. Uncertainty of ocean wave hindcasts due to wind modelling. J. Offshore Mech. Arctic Eng. 117, 294-297.

Van der Westhuysen, A.J., M. Zijlema and J.A. Battjes, 2007: Nonlinear saturation based whitecapping dissipation in SWAN for deep and shallow water, Coast. Engng., 54, 151-170

The WAMDI group. 1988. The WAM model - A third generation ocean waves prediction model. J.Phys. Ocean., i8:I776-1810.

The WISE Group- Cavaleri L. "Wave Modelling- The State of the Art", Progress in Oceanography, vol. 75, issue 4 , 2007 